\title{
Identification the First Priority over Effective Factors in Occurrence of Building Construction Accidents with Employing the Analytical Hierarchy Process Method, and Expert Choice Software
}

\author{
Mostafa Adelizadeh \\ Faculty of Engineering \\ Department of Industrial \\ Engineering \\ Energy Institute of Higher \\ Educations, Saveh, Iran
}

\author{
Zahra Salehi Zanjani \\ Faculty of Engineering \\ Department of Industrial \\ Engineering \\ Energy Institute of Higher \\ Educations, Saveh, Iran
}

\author{
Yossef Yasi \\ Faculty of Engineering \\ Department of Industrial \\ Engineering \\ Energy Institute of Higher \\ Educations, Saveh, Iran
}

\begin{abstract}
In this article- based on previous studies, applying a questionnaire with 81 parameters, and asking experts who mainly were labor inspectors and official judiciary experts on building construction accidents- 5 crucial factors and 13 extrinsic factors effecting on building construction's safety has been identified, and then for determining the amount of effectiveness of each factors on safety with analyzing the data with AHP method ${ }^{1}$, and based on 3 main experts' comments.

Findings: the primary criterion- the height working $(\mathrm{H})$ with weight 0.438 - is the primary factor in building construction accidents. The sub-criterion- falling from scaffolding (H4) with relative weight 0.433 and combined weight 0.190 takes the first rank, and lack of edges protection [unprotected edge] $(\mathrm{H} 2)$ with relative weight 0.342 and combined weight 0.150 are put in second position. After the height working, the criterion of excavation (G) with weight 0.262 is the second factor in occurrence of accidents. The sub-criterion of digging without protection (G1) with relative weight 0.571 and combined weight 0.149 takes the third place and sub-criterion inadequate training (C1) with relative and combined weight 0.137 has the fourth position.

Conclusion: according to the findings, we can clearly state that the practical approach to increase safety and avoid accidents in building construction site becomes readily obtainable by using safety equipment in height working, using protection in the edges to prevent falling, and considering more safety measures in excavation time like testing the soil resistance and the strength of neighbor buildings, and finally safety training.

Key words: building construction site, AHP method, risk reduction
\end{abstract}

Keywords

Expert Choice Software, Analytical Hierarchy Process

\footnotetext{
${ }^{1}$ A method developed by Thomas L. Saaty (1980) for organizing and analyzing complex decisions based on mathematics.
}

\section{INTRODUCTION}

Nowadays, one of the most considerable challenges in the world- especially in developing countries- is occupational accidents. According to the statistics published by International Labour Organization- there are around 2.3 million fatalities annually owing to job-related risks that put enormous costs on states' economics. Among those, the works associated to the building construction sector are most important jobs, yet are most dangerous ones. The building sector in our country refers to the economy's engine and the employment too, but unfortunately for insensible behaviors over safety matters in building construction site it includes the major numbers of all accidents in the country that is relatively high in comparison with the global statistics, and brought financial damages and loss of human capitals [1]. So, finding the decisive factors in building construction accidents for providing controlling approaches can decrease the fatalities and financial damages.

Maria Martinez et al., 2018 in the article "building information modeling and safety management" emphasized that construction safety requires care and planning through the project lifecycle, from the design phase to the maintenance. Initial attempts to improve $\mathrm{OHS}^{2}$ consider the safety aspects in the design phase and the development of manual safety processes in the execution phase. Potential safety hazards can be automatically identified and corresponding prevention methods can be applied using an automated approach [2].

Gabriel Raviv et al., 2017 in the article "AHP-based analysis of the risk potential of safety incidents: case study of carne in the construction industry" indicated that due to increase in the number of fatal incidents in construction sites related to improperly applying tower-crane, the article proposes new measures to potentially assist to prevent and minimize the related incidents with crane in construction industry [3].

\footnotetext{
${ }^{2}$ Occupational Health and Safety
} 
Zhou et al., 2017 in an article proposed an Internet-of-Thingsbased (IOT-based) safety barrier warning system to achieve a safer underground construction site [4].

In an article with the subject of "methodology of improving occupational safety in the construction industry on the basis of the TWI $^{3}$ program" published by Katarzyna Misiurek \& Bartosz Misiurek 2017 analyzed the importance of training in construction industry. The article shows how a preventative approach to ensuring safety has developed over the years. It has been proved that human errors, and not technical problems, have the greatest impact on the occurrence of accidents. The findings infer that the lack of or poorly led training, badly defined and developed work standards and also lack of supervision of employees- are the three main root causes of human errors. Conclusions were used to develop a methodology of improving occupational safety in the construction industry. The developed methodology is based on the selected components from the TWI program and contributes to the elimination of problems associated with the three main root causes of human errors [5].

Chia-Wen Liaoa 2016 in the article with special approach named as 'inattentional blindness' assessed the reducing occupational injuries in construction industry. Many construction accidents are caused by carelessness or inattentiveness, and this is like blindness. Since construction workers have to perform multiple tasks, they can be focused on their main task and ignore dangers in their environment, a condition known as "inattentional blindness" [6].

Luis Fernando Alarcon et al. (2016) in the article "Strategies for improving safety performance in construction firms" showed that in general, the higher the percentage of prevention practices implemented in a strategy, the lower the accident rate. However, the analysis of the combined effect of prevention practices indicated that the choice of the right combination of practices was more important than just the number of practices implemented [7].

David Oswald et al. (2015) in an article with the subject 'accident investigation on a large construction project' indicated that unsafe acts are believed to account for approximately 80 to 90 percent of accidents. The paper will investigate the issue through exploring the reasoning behind the unsafe acts that resulted in a minor accident on a large construction project in the UK. The construction industry needs to shift its safety management effort towards the understanding and elimination of unsafe acts despite them being more difficult to identify and prevent than unsafe conditions. Changing intentional unsafe behaviors is one of the next steps for improving health and safety of the industry, and the insights from the paper add to the knowledge of why these unsafe acts occur [8].

Chia-Wen Liao (2012) in an article with subject 'pattern analysis of seasonal variation in occupational accidents in the construction industry' mentioned that there are some patterns of occupational fatalities in the construction industry. During summer, the risk of fall accidents among workers of age 21-40 and 41-60 is very high. During winter, the increased risk of fallrelated incidents due to unpredictable wet weather conditions should be managed [9].

\footnotetext{
${ }^{3}$ Training Within Industry
}

Antonio Lopez Arquillos et al. (2012) in an article recommended that the severity of accidents was related to variables including age, CNAE (National Classification of Economic Activities) code, size of company, length of service, location of accident, day of the week, days of absence, deviation, injury, and climatic zones; and with analyzing the date they concluded that a large company is not always necessarily safer than a small company in the aspect of fatal accidents [10].

\section{METHODOLOGY}

This article is an analytical study that significant factors in building construction accidents have been analyzed. First, based on previous studies and articles we extracted effective factors on building construction accidents; then taking into account the experts' comments who were all labor supervisors and the official judiciary experts in occupational accidents in this project to screening and prioritizing the factors [parameters], and the criteria and sub-criteria has been specified. The number of optimized questionnaire was calculated by Cochran's theorem ${ }^{4}$. So the number of questionnaire for desirable answer was 44 , in sample size 50. In this study, 50 questionnaires for completion have been sent to the safety experts in construction sector including labor supervisors and official judiciary investigators for [building] accidents, and in response 48 completed questionnaires have been received that among them 46 papers were accepted, actually 95\%. Also for ensuring the answered questions, we estimated the reliability of questionnaire. For checking the reliability level we used the $\operatorname{SPSS}^{5}$ software to calculate the Cronbach alpha coefficient. This coefficient was 0.98 that means it is acceptable when $\leq 0.7$, so the results have the acceptable reliability level.

By screening and prioritizing the factors, we have 5 primary criteria and 13 sub-criteria. Then by employing AHP method, the analytical hierarchy structure for pairwise comparison of criteria was drawn. In every pairwise comparison based on deciders' personal judgments, and comparison matrix we could calculate the relative weight of every factor; then in Expert Choice software we had the goal and criteria, and the alternatives in every level have been compared with the higher level by 3 main experts, and relative weight has been calculated. So with synthesizing every relative weight for 3 experts, the absolute weight can be reached. As the highest weight that inferred the most hazardous works in building construction site, then the safety measures and appropriate controlling approach have been proposed.

Establishing the analytical hierarchy structure in this study

First step in AHP is establishing of analytical hierarchy structure or tree. To reach that, first the criteria and choices of study and its alternatives must be identified, and then the significant factors in building construction accidents were screened and classified with using the questionnaires and experts' comments. After additional consideration, 5 primary effective factors [criterion] and 13 sub-components [sub-criterion] were selected

\footnotetext{
${ }^{4}$ In statistics- devised by William G. Cochran- is a theorem used to justify results relating to the probability distributions of statistics that are used in the analysis of variance.

${ }^{5}$ Statistical Package for the Social Sciences
} 
as our study's criteria. In Table 1 , the lists of criteria and sub-

criteria and representative symbols were presented.

Table 1: list of study's criteria

\begin{tabular}{|c|c|c|c|c|}
\hline No & Criterion & symbol & Sub-criterion & Symbol \\
\hline 1 & Cultural characteristic & $\mathrm{C}$ & Inadequate training & $\mathrm{C} 1$ \\
\hline \multirow{4}{*}{2} & \multirow{4}{*}{ Height working } & \multirow{4}{*}{$\mathrm{H}$} & Unsafe ladders & H1 \\
\hline & & & Lack of edges protection & $\mathrm{H} 2$ \\
\hline & & & Not using the safety equipment & $\mathrm{H} 3$ \\
\hline & & & Falling from scaffolding & $\mathrm{H} 4$ \\
\hline \multirow{2}{*}{3} & \multirow{2}{*}{$\begin{array}{l}\text { Variation activities in } \\
\text { building construction }\end{array}$} & \multirow{2}{*}{$\mathrm{P}$} & Multiple task to do & P1 \\
\hline & & & Lack of coordination and cooperation between contractors & $\mathrm{P} 2$ \\
\hline \multirow{3}{*}{4} & \multirow{3}{*}{ Excavation } & \multirow{3}{*}{$\mathrm{G}$} & Digging without protection & G1 \\
\hline & & & Digging without noticing the soil resistance & G2 \\
\hline & & & Crane drivers' carelessness in digging process & G3 \\
\hline \multirow{3}{*}{5} & \multirow{3}{*}{ Lack of legal backing } & \multirow{3}{*}{ A } & Refusing law enforcement by employers & A1 \\
\hline & & & No legal guarantee & $\mathrm{A} 2$ \\
\hline & & & No strict supervision & A3 \\
\hline
\end{tabular}

Now, after identifying the criteria and the sub-criteria, establishing the analytical hierarchy structure can be done.
Figure 1 illustrates the study's analytical hierarchy structure with using Expert Choice software.

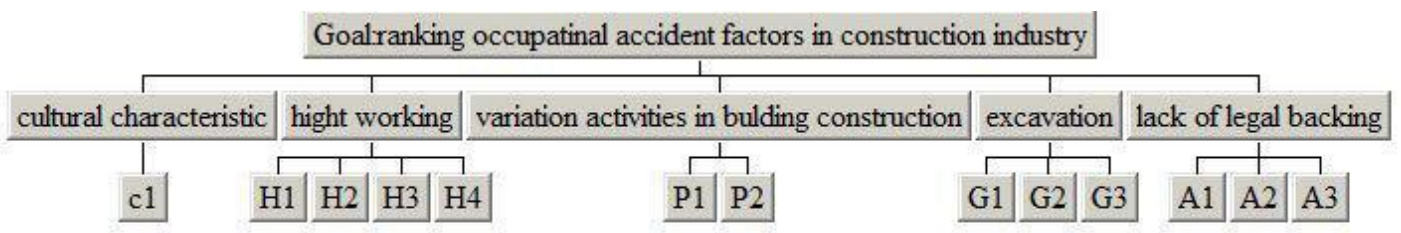

Figure 1: the study's analytical hierarchy structure with Expert Choice software

Calculating the relative weight of the study's primary criteria After identifying the analytical hierarchy structure, the calculation and assessment the weight of study's criteria relative to the goal must be done. For this, first we did questionnaire of pairwise comparisons of criteria relative to the goal. After completing the questionnaire, for assess and calculating the relative weight, those comparisons are put in the Expert Choice software. If the pairwise comparisons matrix inconsistency ratio of the primary criteria is acceptable, it ca be presented; otherwise, the questionnaires of pairwise comparison must be returned to the experts to be reviewed. Figure 2 illustrates the pairwise comparison matrix from respondents [participants] and its consistency ratio in Expert Choice software. The weight and rank from calculating pairwise comparison matrix of the primary criteria relative to the goal illustrate in figure 3 .

\begin{tabular}{|c|c|c|c|c|c|}
\hline \multicolumn{6}{|c|}{ Compare the relative importance with respect to: Goal:ranking occupatinal acciden f factors in construction industry } \\
\hline & \multicolumn{5}{|c|}{ cullural ch: hight worki variation a excavation lack of legis } \\
\hline cultural charadteristic & & 3.30193 & 1.5874 & 2.62074 & 2.62074 \\
\hline hight working & & & 4.16017 & 2.28943 & 5.03968 \\
\hline variation activities in bulding construction & & & & 2.51984 & 1.65096 \\
\hline excavation & & & & & 4.16017 \\
\hline lack of legal backing & Incon: 0.02 & & & & \\
\hline
\end{tabular}

Figure 2: the pairwise comparison matrix for primary criteria relative to the goal

Priorities with respect to:

Goatranking occupatinal accident factors in construction industry
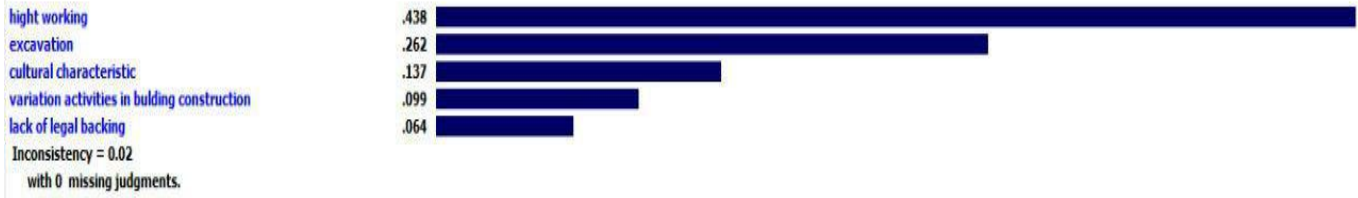

Figure 3: the rank of primary criteria relative to their weights 
As it can be noticed among the primary criteria, the height working gets the weight 0.438 , so it has the highest importance over the criteria. Criteria of excavation with weight 0.262 and criteria of cultural characteristic with weight 0.137 , the variation activities in building construction with weight 0.099 , and the lack of legal backing with weight 0.064 are placed in the next ranks respectively.

Calculating the sub-criteria of height working
The questionnaire of pairwise comparison for sub-criteria of height working, their relative weight, and the rank of their importance are illustrated in figure 4 and figure 5 respectively. As it presented, the sub-criterion of falling from scaffolding (H4) with weight 0.433 takes the first place. The sub-criterion of lack of edges protection (H2) with weight 0.342 , not using the safety equipment (H3) with weight 0.121 , and unsafe ladders (H1) with weight 0.105 are placed in the next ranks.

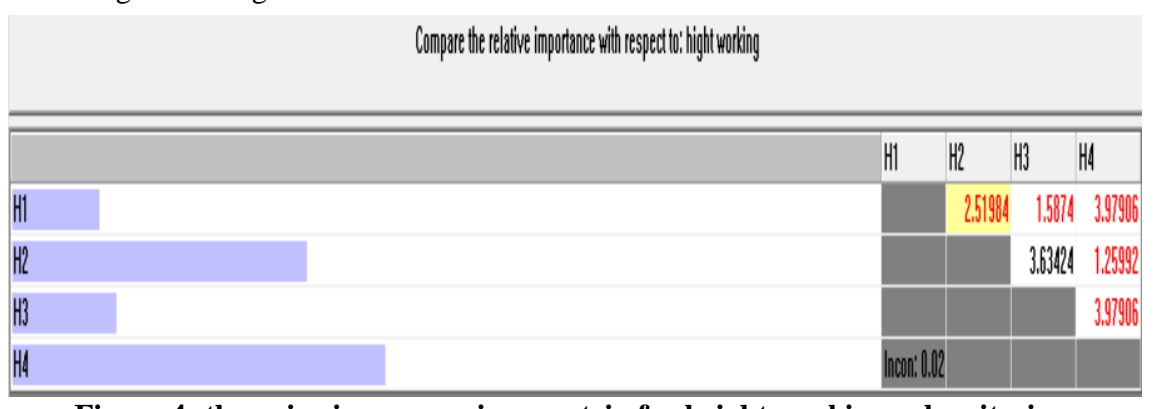

Figure 4: the pairwise comparison matrix for height working sub-criterion

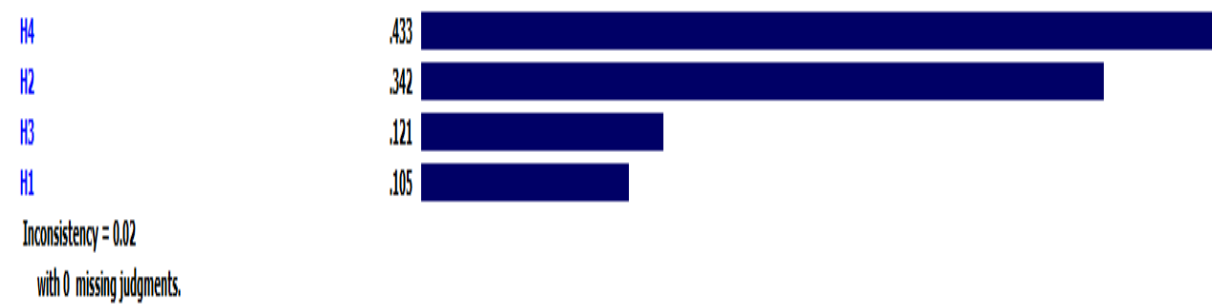

Figure 5: the rank of importance in sub-criteria of height working

\section{Calculating the sub-criteria of excavation}

The questionnaire of pairwise comparison for sub-criteria of excavation, their relative weight, and the rank of their importance are illustrated in figure 4 and figure 5 respectively.
As it presented, the sub-criterion of digging without protection (G1) with weight 0.571 is more important than the sub-criterion of crane drivers' carelessness (G3) with weight 0.288 . Also, the sub-criterion of digging without noticing the soil resistance $(\mathrm{G} 2)$ with weight 0.143 has less importance than G1 and G2.

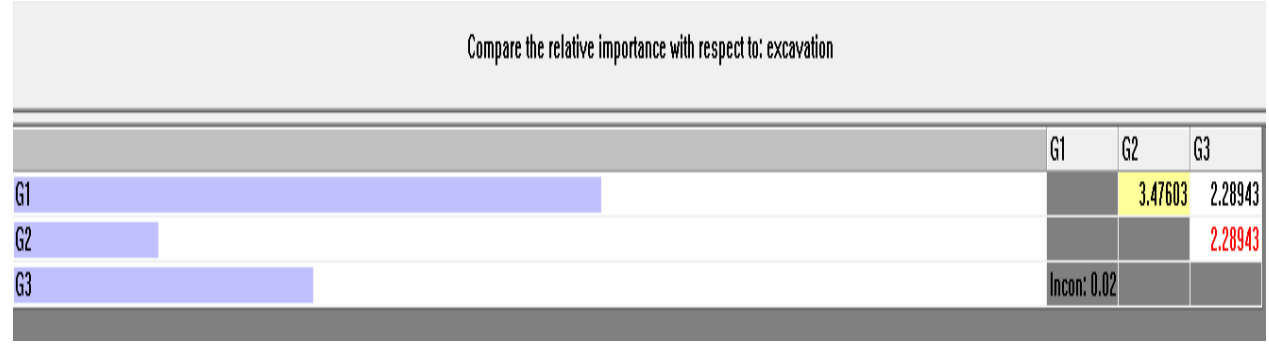

Figure 6: the pairwise comparison matrix for sub-criteria of excavation

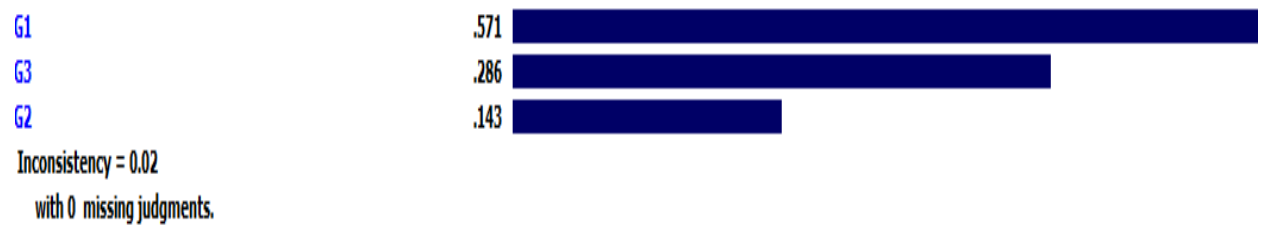

Figure 7: the rank of importance in sub-criterion of excavation 
Calculating the combined [synthesized] weight of sub-criterion

For calculating the combined weight of each sub-criterion, we should multiply the relative weight of primary criterion by relative weight of that sub-criterion.
Note: since the cultural characteristic has just one sub-criterioninadequate training $\mathrm{C} 1$ - so the combined weight and relative weight is equal.

In figure 8, the study's sub-criteria based on their combined weight respectively are illustrated.

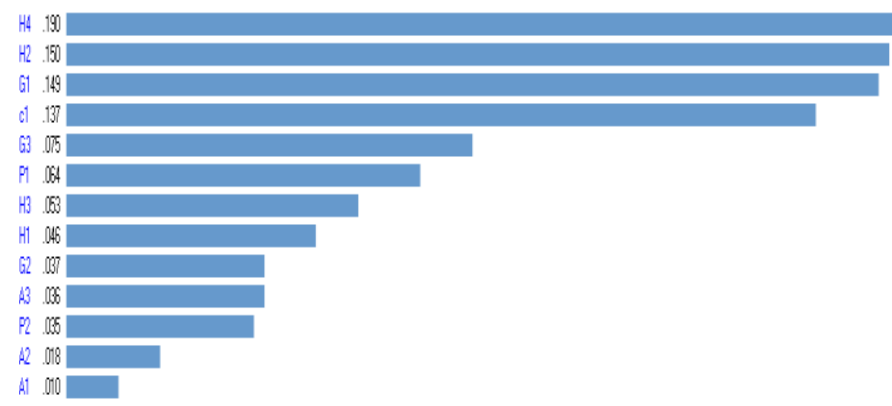

Figure 8: the -sub-criteria's rank of importance

As it presented, the sub-criterion of falling from scaffolding (H4) carries the considerable weight (0.190) over the study's sub-criteria; it has been demonstrated that this issue [factor] is the most important variable in this paper.

The lack of edges protection $(\mathrm{H} 2)$ with combined weight 0.150 and the digging without protection (G1) with combined weight
0.149 take the second and third place respectively. Then, inadequate training with combined weight 0.137 is placed in the next rank.

Table 6: the -sub-criteria's rank of importance

Table 6: the -sub-criteria's rank of importance

\begin{tabular}{|c|c|c|}
\hline sub-criteria & combined weight & calculations of relative weight \\
\hline H4 & 0.190 & $0.190=0.438 \star 0.433$ \\
\hline H2 & 0.150 & $0.150=0.438 \star 0.342$ \\
\hline G1 & 0.149 & $0.149=0.262 \star 0.571$ \\
\hline C1 & 0.137 & $0.137=0.137 \star 1$ \\
\hline G3 & 0.075 & $0.075=0262 \star 0.288$ \\
\hline P1 & 0.064 & $0.064=0.099 \star 0.645$ \\
\hline H3 & 0.063 & $0.063=0.438 * 0.121$ \\
\hline H1 & 0.046 & $0.046=0.438 \star 0.105$ \\
\hline G2 & 0.037 & $0.037=0.262 \star 0.143$ \\
\hline A3 & 0.036 & $0.036=0.064 \star 0.562$ \\
\hline P2 & 0.035 & $0.035=0.099 \star 0.355$ \\
\hline A2 & 0.018 & $0.018=0.064 \star 0.279$ \\
\hline A1 & 0.01 & $0.010=0.064 \star 0.159$ \\
\hline
\end{tabular}

\section{CONCLUSION}

The primary criterion- the height working- allocated the highest rank with weight 0.438 in occurrence of building construction accidents, and this fact shows the necessity of implementing safety measures in dangerous work conditions in height like fall arrest system, safety restraint system, rope access, lanyard, safety belt, harness, self-locking hook [karabiner], shock absorber, etc. that is precisely specified in occupational safety regulations of the administration of labor inspection [Ministry of Cooperatives, Labour, and Social Welfare]. After that, the criterion of excavation with weight 0.262 takes the second place; therefore, obediently following the safety recommendations in digging and excavation project including putting adequate protection, crane drivers' carefulness, and noticing the soil resistance has considerable significance. After height working and excavation factors, the cultural characteristic with weight 0.137 takes the third position, that it shows the importance of training to prevent the accidents. The variation activities in building construction $(\mathrm{P})$ with weight 0.099 , and the lack of legal backing (A) with weight 0.060 are put in the next ranks; it is reasonable to infer that the coordination and cooperation of involved people in building construction site including various contractors, and the importance of legal backing like strict supervision by project supervisors during construction for properly executing standard building plan and supervision of official labor inspectors for enforcing the safety standards, and giving the absolute legal guarantee, encouraging and pave the way for contractors to comply with the regulations hold an influential position. Among them, sub-criterion falling from 
scaffolding (H4) with relative weight 0.433 and combined weight 0.190 takes the first place and the lack of edges protection with relative 0.342 and combined weight 0.150 are put on second rank; it clearly reaffirms the importance of following the safety recommendations to prevent falling and close the edges with protection. The sub-criterion of digging without protection (G1) with relative weight 0.571 and combined weight 0.149 has the third place that it shows the importance of using the fence and shield, especially in the case of probably soil failure it is necessary to install piling and protective strong barrier. Then, sub-criterion of inadequate training $(\mathrm{C} 1)$ with relative and combined weight 0.137 is placed in the fourth rank, and then Crane drivers' carelessness (G3) with relative weight 0.288 and combined weight 0.075 takes the last position; it clearly indicates that employing the experienced and careful crane driver is fairly important.

Recommendations for further research As in this study we employed the AHP method for screening and prioritizing the criteria and every criterion was independently considered, we warmly recommend the $\mathrm{ANP}^{6}$ method for evaluating the criteria and to achieve more accurate results, and internal relation among criteria must be thoroughly examined. So, with specifying the ratio of mutual dependency among criteria and alternatives, the relative importance of each choice in its own level- like AHP method- with using a set of pairwise comparison can be assessed.

\section{REFERENCES}

[1] Amirkabir Journal of Science \& Research Civil and Environmental Engineering, Vol. 48, No. 3, Fall 2016, pp. 217

[2] Maria D. Martinez-Aires, Monica Lopez-Alonso, Maria Martinez-Rojas, building information modeling and safety management Journal of Safety Science, volume 43 (2012) pages $11-18$

[3] Gabriel Raviv, Aviad Shapira, Barak Fishbain , AHP-based analysis of the risk potential of safety incidents: Case study of cranes in the construction industry ,Journal of Safety Science, volume 91, January 2017, pages 298-309, by

[4] C. Zhou, L. Y. Ding, safety barrier warning system for underground construction sites using Internet-of-Things technologies ,Journal of Safety Science, volume 83, November 2017, pages 372-382

[5] Katarzyna Misiurek, Bartosz Misiurek, methodology of improving occupational safety in the construction industry on the basis of the TWI program ,Journal of Safety Science, volume 92, February 2017, Pages 225-231

[6] Chia Wen Liao, reducing occupational injuries attributed to inattentional blindness in the construction industry, Tsung Lung Chiang, Journal of Safety Science, volume 89, November 2016, Pages 129-137

[7] Diego Acuna, Seven Diethelm, strategies for improving safety performance in construction firms ,Eugenio Pellicer ,Journal of Science Direct, volume 94, 2016, pages 107-118
[8] David Oswald, Simon Smith, Fred Sherratt , accident investigation on a large construction project, Procedia Manufacturing, volume 3 (2015) pages 1788 - 1795

[9] Chia-Wen Liao, pattern analysis of seasonal variation in occupational accidents in the construction, Journal of Science Direct, volume 29, 2012, Pages 3240-3244

[10] Lopez Arquillos, A. Rubio Romero, Juan. C. Gibb, Alistair. G. F. , analysis of construction accidents in Spain, Journal of Safety Research, volume 43(2012) pages 381-388, 20032008

\footnotetext{
${ }^{6}$ Analytical Network Process
} 